Dossier: Mujeres y Educación en la Universidad Nacional

Red de Mujeres Investigadoras de la Universidad Nacional (UNA)

\title{
Ser mujer docente. Significados, y sentidos de estudiantes de licenciatura en ciencias sociales, en el desarrollo de su práctica pedagógica
}

\author{
Ingrid Marcela Cuervo Méndez \\ Fundación Universitaria del Área Andina, Colombia \\ icuervo@areandina.edu.co \\ https://orcid.org/0000-0003-4363-6490
}

Recibido: 4 de agosto de 2020

Aceptado: 10 de noviembre de 2020

Resumen: El trabajo tiene como objetivo caracterizar las creencias de los estudiantes de licenciatura en Ciencias Sociales de la Fundación Universitaria del Área Andina acerca de la relación docencia-género para dar cuenta del significado y sentido otorgado al ser mujer docente. Para esto se realizó un análisis documental de las reflexiones entregadas en la Práctica pedagógica que cursan las estudiantes antes de recibir su título profesional, un grupo focal y una encuesta auto diligenciada (para la segunda fase 2020). Se encuentra que coexisten varias perspectivas y énfasis sobre la relación mujer-docente, de tal manera que algunas siguen refiriendo a lo femenino del cuidado, y otras al ser profesional. A partir de estas conclusiones se propone abrir nuevos espacios de reflexión e investigación educativa de la perspectiva de género, con el fin de que contribuyan al campo y enriquezcan la formación del profesorado.

Palabras Claves: Género, representaciones sociales, subjetividad, práctica pedagógica.

\section{Being a woman-teacher. Meanings, and senses of undergraduate students in social sciences, in the development of their pedagogical practice}

Summary: The objective of the work is to characterize the beliefs of the bachelor's degree students in Social Sciences of Fundación Universitaria del Área Andina

$$
\text { (c) (i) (9) }
$$

La Revista Estudios es editada por la Universidad de Costa Rica y se distribuye bajo una Licencia Creative Commons Atribución-NoComercial-CompartirIgual 3.0 Costa Rica. Para más información envíe un mensaje a 
Dossier: Mujeres y Educación en la Universidad Nacional

Red de Mujeres Investigadoras de la Universidad Nacional (UNA)

about the teaching-gender relationship to account for the meaning and meaning given to being a female teacher. For this, a documentary analysis of the reflections delivered in the Pedagogical Practice that students take before receiving their professional title, a focus group and a self-completed survey (for the second phase 2020) was carried out. It is found that various perspectives and emphasis on the woman-teacher relationship coexist, in such a way that some continue to refer to the feminine of care, and others to being professional. Based on these conclusions, it is proposed to open new spaces for educational reflection and research from the gender perspective, in order to contribute to the field and enrich the training of teachers.

Key Words: Gender, social representations, subjectivity, pedagogical practice

\section{Introducción}

El género implica una construcción social en las que se asignan cualidades, atributos, y expectativas, teniendo como primer criterio la diferencia biológico sexual. La pedagogía -en tanto ciencia- es una forma de saber sexuado con efectos analíticos, porque conceptualiza lo que se espera en el universo femenino y masculino, prácticos, porque configura relaciones entre hombres y mujeres, y políticos, cuestionando la naturalización de la dicotomía masculino-público-objetivo y femenino-privado-subjetivo.

Aproximarse a la comprensión de la relación género - saber pedagógico teniendo presente la necesidad de reconocer que estos conceptos forman parte de la configuración del docente tanto en su cotidianidad como en su vida personal y profesional. Estos aspectos contribuyen a (re)pensar la relación docencia-género, y por esta vía (re)configurar la mirada alrededor del sujeto femenino con agencia, saber, y capacidad de producir nuevas prácticas y nuevas relaciones, más allá de reproducir y cuidar (el saber y a los sujetos con los que interactúa en aula).

\section{(C) $(0 \odot$}

La Revista Estudios es editada por la Universidad de Costa Rica y se distribuye bajo una Licencia Creative Commons Atribución-NoComercial-CompartirIgual 3.0 Costa Rica. Para más información envíe un mensaje a 
Dossier: Mujeres y Educación en la Universidad Nacional

Red de Mujeres Investigadoras de la Universidad Nacional (UNA)

Los conceptos de género y saber pedagógico acompañaron las conversaciones sostenidas en el proceso de tutoría de la práctica pedagógica que forma parte del proceso educativo de licenciados en ciencias sociales de la Fundación Universitaria del Área Andina. Por ello, el artículo involucra un proceso macro de reflexión sobre el significado y sentido de la mujer docente. El objetivo principal es conversar de manera colectiva sobre cómo la escuela se configura como magma de subjetividades en las que es posible reproducir o transformar valores y actitudes androcéntricos que legan a la mujer papeles secundarios en la educación y en las relaciones de poder.

En el proceso de formación de docentes las preguntas por los sujetos de aprendizaje, las identidades profesionales que se impulsan y la relación entre género y docencia que se identifica entre estos estudiantes son una oportunidad para cuestionar la supuesta neutralidad axiológica de la(s) ciencia(s) y el logocentrismo occidental; este apela a la lógica categorial que refuerza oposiciones como las de la racionalidad masculina y emocionalidad femenina, y establece la autoridad legítima de lo masculino para controlar las relaciones humanas, y a la naturaleza misma (por sus atributos feminizados). Entender que cada sociedad elabora la relación género - poder, y que cada persona incorpora a su voz la voz de la cultura "donde se manifiesta dicha relación" (Bolaños y Jiménez, 2007, p. 87) demanda una aproximación a los contextos de los docentes en formación.

La construcción de las identidades profesionales de los docentes empieza con sus experiencias previas en escenarios institucionales, y los contextos socioculturales y educativos, previos al ser profesional (Yuan y Burns, 2017, p. 19), por lo que las conversaciones se ocuparon de las subjetividades, expectativas, incertidumbres y deseos. La comprensión de cómo se aprenden valores y actitudes androcéntricos o igualitarios debió necesariamente incluir la revisión de las 
Dossier: Mujeres y Educación en la Universidad Nacional

Red de Mujeres Investigadoras de la Universidad Nacional (UNA)

instituciones familia y escuela, pues en la segunda se refuerza o cuestiona lo que se aprende en la primera.

Al respecto Bronfenbrenner (2002) señala que la relación entre microsistemas (familia y escuela, para nuestra reflexión) son el marco de desarrollo y aprendizaje, pues conductas y pautas aprendidas en la primera pueden tener repercusión en la segunda, y a la inversa, siendo esta una relación bidireccional o unidireccional, los aprendizajes androcéntricos de casa no se transforman, pese al ejercicio de educación igualitaria de la escuela.

Es así como las preguntas guía fueron: ¿Cuáles relaciones docencia-género subyacen en las creencias de los estudiantes de licenciatura en Ciencias Sociales de la Fundación Universitaria del Área Andina? y ¿Cuáles significados y sentidos le otorgan al ser mujer-docente los estudiantes de licenciatura en Ciencias Sociales de la Fundación Universitaria del Área Andina? El propósito central de la reflexión fue caracterizar las creencias de los estudiantes acerca de la relación docenciagénero para dar cuenta del significado y sentido otorgado al ser mujer docente.

Para ello, los propósitos secundarios fueron: identificar los aprendizajes de los estudiantes de licenciatura en Ciencias Sociales, alrededor de la diferencia sexual y de género, obtenidos en la familia y la escuela; reconocer la existencia de unidades discursivas diferenciales respecto a habilidades, actitudes y saberes necesarios para desempeñarse como licenciados en Ciencias Sociales; y caracterizar habilidades y retos percibidos por los estudiantes de licenciatura en Ciencias Sociales sobre el rol docente.

\footnotetext{
(c) (i) (2) (2)

La Revista Estudios es editada por la Universidad de Costa Rica y se distribuye bajo una Licencia Creative Commons Atribución-NoComercial-CompartirIgual 3.0 Costa Rica. Para más información envíe un mensaje a revistaestudios.eeg@ucr.ac.cr.
} 
Dossier: Mujeres y Educación en la Universidad Nacional

Red de Mujeres Investigadoras de la Universidad Nacional (UNA)

\section{Marco Conceptual}

Izquierdo (1994) señala que sobre el concepto género hay una prolífica producción desde casi todos los ámbitos del saber: la sociología y el género como producto de la socialización; la psicología y los estereotipos sexogenéricos; la ciencia política y la reflexión sobre relaciones de dominación y subordinación fundadas en características biológicas; la administración pública y el llamado a incluir la perspectiva de género en las actuaciones del Estado -bajo el nombre de transversalización de la perspectiva-, entre otros.

El género puede entenderse como

el conjunto de ideas, representaciones, prácticas y prescripciones sociales que una cultura desarrolla a partir del reconocimiento de la diferencia anatómica entre los sexos. El género es la constatación cultural de la diferencia sexual, y simboliza lo que es "propio" de los hombres (lo masculino) y lo que es "propio" de las mujeres (lo femenino); pero además de ser un mandato cultural también implica procesos psíquicos; y toda esa complejidad se arma como un conjunto de creencias y prácticas que jerarquizan y discriminan a los seres humanos. Lamas, M. (2007, p. 3).

Esto implica que el género es una construcción histórica, pues en cada época cambia lo que se considera "propio" de cada sexo, aunque la diferencia biológica permanece inmutable; y también es una construcción cultural basada en el reconocimiento de la diferencia biológica entre los sexos. Elisabeth Badinter, citada por Altamirano (1993) resalta que la diferenciación entre lo masculino y lo femenino (género) se funda en la lógica de los contrarios que forma parte de la construcción del pensamiento dicotómico-dualista de la cultura occidental. A las categorías dicotómicas de sexo biológico (hombre/mujer) se le asignan atributos masculinos/femeninos, de tal suerte que confluyen tres instancias básicas: la asignación de género, la identidad de género y el papel o rol de género. (Lamas, 2006, pp. 35-36)

\section{(c) (i) (2)}

La Revista Estudios es editada por la Universidad de Costa Rica y se distribuye bajo una Licencia Creative Commons Atribución-NoComercial-CompartirIgual 3.0 Costa Rica. Para más información envíe un mensaje a 
Dossier: Mujeres y Educación en la Universidad Nacional

Red de Mujeres Investigadoras de la Universidad Nacional (UNA)

Esta esencialización reductiva del género contribuye a la biologización del género y presuponen la subordinación de lo femenino frente a lo masculino, otorga a todo aquello feminizado la tarea de cuidar y atender a los otros, resalta la debilidad y vulnerabilidad, mientras reconoce a lo masculinizado el rol de protección y fuerza. Esta configuración ideológica y simbólica conduce a que todos los sujetos sean generalizados y con ello se establezca una serie de expectativas sobre el ser, el hacer y el estar o sobre los roles de género a desplegar en los diferentes escenarios de la vida.

Tabla 1. Dicotomía asociada a la biologización del género

\begin{tabular}{|c|c|c|}
\hline Dimensión & Masculino & Femenino \\
\hline \multirow{3}{*}{ Ser-Emocionalidad } & Firmeza & Sensibilidad \\
\hline & Decisión & Temor \\
\hline & Egoísmo & Altruismo \\
\hline \multirow{4}{*}{ Ser-Relacionamiento } & Autonomía & Relación \\
\hline & No habla de emociones & Procura comunicarse \\
\hline & Racional & Emocional \\
\hline & Agresividad & Docilidad \\
\hline \multirow{7}{*}{$\begin{array}{l}\text { Epistemológico - Conocer - } \\
\text { Capacidades intelectuales }\end{array}$} & Conocimiento & Intuición \\
\hline & Razón & Emoción \\
\hline & Abstracción & Concreción \\
\hline & Objetividad & Subjetivación \\
\hline & Categorías & Inter - Transdiciplinariedad \\
\hline & Generalización & Detalles \\
\hline & Ciencias exactas & Artes y humanidades \\
\hline \multirow{6}{*}{ Poder - Estar } & Dinamismo & Pasividad \\
\hline & Público & Privado \\
\hline & Competición & Cooperación \\
\hline & Centralización & Red \\
\hline & Autoritarismo & Consenso \\
\hline & Administración & cuidado \\
\hline
\end{tabular}

Fuente: Elaboración propia a partir de la lectura de Boff \& Muraro (2004) y Altamirano (1993)

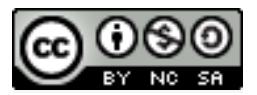

La Revista Estudios es editada por la Universidad de Costa Rica y se distribuye bajo una Licencia Creative Commons Atribución-NoComercial-CompartirIgual 3.0 Costa Rica. Para más información envíe un mensaje a revistaestudios.eeg@ucr.ac.cr. 
Dossier: Mujeres y Educación en la Universidad Nacional

Red de Mujeres Investigadoras de la Universidad Nacional (UNA)

Cuando Simone de Beauvoir manifiesta que "no se nace mujer, una llega a serlo"i, reconoce que ni la feminidad ni la masculinidad dependen de la naturaleza biológica, sino que se adquieren culturalmente, por lo que el determinismo biológico justifica las desigualdades de género, a la vez que invisibiliza, desconoce y cosifica la existencia y participación de la mujer y lo femenino en el mundo. Lauretis (1989) indica que el género es el producto de varias tecnologías sociales (por ejemplo, el cine, la televisión), discursos institucionales, epistemologías y prácticas de la vida cotidiana; es decir, el despliegue de una tecnología política (en el sentido de Foucault, de operaciones institucionales, sociales, y personales que politizan el cuerpo) tiene efectos en los cuerpos, comportamientos y relaciones sociales.

Por ello, superar la idea de género como atributo o asignación de acuerdo al sexo, posibilita un acercamiento al género como performatividad y como acciones que se incorporan en las prácticas de la vida cotidiana. Estos son definidos y aprendidos, por lo que estas construcciones sociales consensuadas alrededor de lo masculino y femenino se pueden modificar. El género, como categoría de análisis entiende que los patrones esencialistas (fundados en las diferencias biológicas) perpetúan la subordinación de la mujer y lo femenino, a la vez que centra el poder en el hombre y lo masculino.

Esta comprensión de que la feminidad/masculinidad no es sólo un rol sino se constituye en un principio organizador de la subjetividad entera, y que esta es construida desde la experiencia, hace indispensable identificar cómo se entiende la subjetividad. Más aún cuando la idea que cada sujeto elabora sobre sí y el otro, y la forma de establecer la interacción entre los sujetos se configura por la subjetividad misma.

\section{(C) $(\Theta \odot$}

La Revista Estudios es editada por la Universidad de Costa Rica y se distribuye bajo una Licencia Creative Commons Atribución-NoComercial-CompartirIgual 3.0 Costa Rica. Para más información envíe un mensaje a 
Dossier: Mujeres y Educación en la Universidad Nacional

Red de Mujeres Investigadoras de la Universidad Nacional (UNA)

Cristancho (2012, p. 3) entiende la subjetividad como la dinámica manera de ser, estar, actuar y situarse ante sí mismo, ante la vida, ante los demás y ante el mundo, que cada uno de nosotros configura de sí. La subjetividad es, entonces, el modo particular de ser de cada persona que se configura en la interacción (con los otros y el mundo) y en la producción de experiencias. Estas últimas, como señala Perrenoud (2007, p. 134) permiten la construcción de una identidad, el reconocimiento de la alteridad, el otro (sujeto) y lo otro (realidad).

De esta forma la subjetividad reconoce la cosmovisión que cada uno tiene frente al mundo, la expresión simbólica y emocional frente a las experiencias, y que permite una formación -acción y efecto de formar o formarse- y modificación de sí mismo y de sus prácticas cotidianas.

En la formación docente, entendida como "proceso en el que se articulan prácticas de enseñanza y de aprendizaje orientadas a la configuración de sujetos docentes/enseñantes" (Achilli, 2000, p. 23) se construyen subjetividades, que pueden -o no- modificarse como producto de la reflexión sobre la acción. Al respecto Schön (2002, p. 40) señala que la reflexión en la acción, y la reflexión sobre la reflexión en la acción tiene el potencial de transformar la acción futura, y por esa vía, la reflexión en la formación docente puede contribuir a transformar las subjetividades de quienes se forman.

En tanto proceso, la formación docente implica una trayectoria que puede iniciar, en el caso de Colombia, en escuelas normales o en las universidades con carreras donde se aprenden o enseñan las: "actividades, interacciones, relaciones que configuran el campo laboral del sujeto maestro o profesor en determinadas condiciones institucionales y sociohistóricas" (Achilli, E, 2000, p. 23)

\section{(C) $(0 \odot$}

La Revista Estudios es editada por la Universidad de Costa Rica y se distribuye bajo una Licencia Creative Commons Atribución-NoComercial-CompartirIgual 3.0 Costa Rica. Para más información envíe un mensaje a 
Dossier: Mujeres y Educación en la Universidad Nacional

Red de Mujeres Investigadoras de la Universidad Nacional (UNA)

La formación docente normalista y universitaria dista en la concepción misma de formación, las bases epistemológicas y el perfil de egreso. Para el caso de los normalistas el interés está más relacionado con que los docentes aprendan a conservar el orden y la disciplina, e inculcar valores; se privilegian metodologías expositivas tendientes al aprendizaje memorístico del conocimiento; seleccionando estrategias y recursos o diseñando materiales didácticos. Quienes se forman en universidades tienen una formación más disciplinar que didáctica (lo que resalta una falsa dicotomía entre saberes/disciplinares y saberes/pedagógicos); trabajan con metodologías más híbridas y tendientes a centrarse en el aprendizaje; y tienen la capacidad de contribuir con diseños curriculares micro y macro.

Sin embargo, lo que es común en estos dos modelos son los aprendizajes que necesariamente confluyen en la formación docente y que Shulman (2015) señala como aprendizaje cognitivo. En este se aprende a pensar como docente e incluye los saberes teórico-metodológicos para desempeñarse en un campo pedagógico específico. Por otra parte, el aprendizaje práctico es en el que se aprende a actuar como profesional, se interiorizan prácticas y formas de relacionamiento con los otros sujetos del entorno escolar. Finalmente, el aprendizaje moral es aquel que potencia la responsabilidad y ética -y vincula al discurso vocacionalista-. Estos aprendizajes permiten que los docentes desarrollen bien su trabajo y/o les permite adquirir y afinar ciertas capacidades y competencias.

Las competencias pueden ser definidas y categorizadas de diferentes modos a través del tiempo, incluyendo conceptos de conocimiento, habilidad, motivaciones, características de la persona, nivel de desempeño de la competencia y contexto de aplicación de la competencia. Sin embargo, lo que interesó en esta reflexión fue el componente motivacional y las características del sujeto para el desempeño en un

\section{(C) $(0 \odot$}

La Revista Estudios es editada por la Universidad de Costa Rica y se distribuye bajo una Licencia Creative Commons Atribución-NoComercial-CompartirIgual 3.0 Costa Rica. Para más información envíe un mensaje a 
Dossier: Mujeres y Educación en la Universidad Nacional

Red de Mujeres Investigadoras de la Universidad Nacional (UNA)

rol específico (el docente). Es decir, los atributos que debe poseer para desplegar su ejercicio profesional de manera competente (Sultana, 2009)

De acuerdo a Lozano y Herrera (2013), una vía para clasificar esos atributos puede ser el de habilidades blandas (que sirven para actuar en las actividades diarias y hacen parte de los rasgos de la personalidad) y duras (que se van adquiriendo a lo largo de la formación, ejercicio profesional, y desarrollo de funciones específicas requeridas). Así mismo, están las habilidades instrumentales que priorizan la utilidad de las acciones para la consecución de un fin, y que combinan habilidades cognitivas, capacidades metodológicas, destrezas tecnológicas y lingüísticas.

Por su parte Villa y Poblete (2007) resaltan la existencia de cualidades que impactan la cooperación y la interacción social lo que posibilita actuar con otros para alcanzar propósitos comunes. A su vez, parten de un proceso de comunicación y aceptación de sentimientos y emociones (propios y ajenos). Estas emociones son de orden interpersonal y permiten establecer vínculos y relaciones estables con los demás, pero se diferencia de las sociales, que Sultana (2009) entiende cómo ese conjunto de conductas, actitudes y comportamientos posibilitan que los sujetos mantengan su autoestima sin menoscabar a las personas con las que se relacionan.

Entonces, se entiende que la formación docente es el proceso de acciónreflexión-acción para aprender intencionalmente un conjunto de discursos, saberes y realidades pedagógicas en el que es tan relevante la formación profesional (del saber saber y saber hacer) como personal (del saber ser y saber estar). Esta formación contribuye a la construcción de una subjetividad -entendida como una dinámica manera de ser que cada uno de nosotros configura de sí y es configurada

\section{(C) $(\Theta \odot$}

La Revista Estudios es editada por la Universidad de Costa Rica y se distribuye bajo una Licencia Creative Commons Atribución-NoComercial-CompartirIgual 3.0 Costa Rica. Para más información envíe un mensaje a 
Dossier: Mujeres y Educación en la Universidad Nacional

Red de Mujeres Investigadoras de la Universidad Nacional (UNA)

en esa constante interacción y producción de experiencias y sentidos (Cristancho, 2012)

\section{Metodología}

Este fue el punto de partida de una reflexión multimodal en la que se privilegió el ejercicio interpretativo, en tanto se propendió por comprender el sentido de los lenguajes, analizar aquello asumido como norma social por los estudiantes en relación al sexo-género y el ser docente, y se indagó acerca de los valores, creencias y significados que forman parte de los marcos de referencia y/o de los patrones para interpretar la realidad simbólica de los estudiantes. (Vasilachis, 2019)

La reflexión tuvo dos momentos y tuvo como finalidad caracterizar las creencias de los estudiantes de licenciatura en Ciencias Sociales de la Fundación Universitaria del Área acerca de la relación docencia-género para dar cuenta del significado y sentido otorgado a la mujer docente.

En la primera fase (2019) se hizo un análisis documental de 42 artículos de reflexión pedagógica, y un grupo focal con los estudiantes del módulo Práctica pedagógica. Los documentos emanan de la práctica de 56 personas que optaron por la modalidad virtual para profesionalizarse, pues algunos son normalistas superiores. Estas personas se encuentran en 13 departamentos, mayoritariamente en zonas rurales, de vocación agrícola y ganadera, y/o de población indígena. E grupo focal se realizó en Montería, teniendo en cuenta la representación numérica de estudiantes en la cercanía de ese Centro de Servicio Universitarioii (CSU) (26 de los 56 estudiantes).

En la segunda fase (2020) se adelantó una encuesta autodiligenciada para identificar habilidades y retos percibidos por los estudiantes de licenciatura en Ciencias Sociales sobre el rol docente, así como los estereotipos de género y las 
Dossier: Mujeres y Educación en la Universidad Nacional

Red de Mujeres Investigadoras de la Universidad Nacional (UNA)

bases de su conformación en la familia y la escuela. Esta fue respondida por 56 estudiantes (34 mujeres y 22 hombres). En la construcción de la encuesta se tuvo presente el método sistémico-estructural para la comprensión de la realidad (lo micro, lo meso y lo macro en la configuración de sentidos y significados), así como la conceptualización de la categoría género, a través del sistema de dimensiones anteriormente señalado.

El cuestionario se dividió en 4 secciones: en la primera se formularon 4 preguntas de caracterización sociodemográfica como: sexo biológico al nacer, edad, pertenencia étnica, y años de experiencia en aula. En la segunda se elaboraron 6 preguntas abiertas sobre rol docente, asociados a cualidades, miedos, acciones para vincularse con los estudiantes, estrategia en el aula y sentido otorgado al ser docente. En el tercer apartado se realizaron 3 preguntas abiertas sobre el aprendizaje de género, identificando si entienden la diferencia entre sexo y género y lo aprendido en la familia y la escuela sobre capacidades, comportamientos, o cosas que no se podían hacer por ser niño o niña. El cuarto apartado tuvo 22 preguntas, en las que los estudiantes asignaron un rol de género a la característica que se estaba preguntando.

Para el análisis de las respuestas abiertas (tanto las del grupo focal como las del cuestionario) se adelantó un proceso de codificación cualitativo basado en el análisis de contenidos. Las respuestas de cada pregunta fueron registradas en una matriz de análisis, en la que se asignó un "M" a las respuestas proporcionadas por mujeres y " $\mathrm{H}$ " a las respuestas de hombres para establecer similitudes y diferencias entre los marcadores lingüísticos de los estudiantes, según su sexo. Luego de un ejercicio de lectura interpretativa se identificaron patrones de respuesta que permitieron la agrupación en unidades de significado. Estas unidades se nominaron,

\section{(C) $(0 \odot$}

La Revista Estudios es editada por la Universidad de Costa Rica y se distribuye bajo una Licencia Creative Commons Atribución-NoComercial-CompartirIgual 3.0 Costa Rica. Para más información envíe un mensaje a 
Dossier: Mujeres y Educación en la Universidad Nacional

Red de Mujeres Investigadoras de la Universidad Nacional (UNA)

según la pregunta, estableciendo una relación de coherencia con la denominación más próxima según los referentes conceptuales empleados en el ejercicio reflexivo.

Tabla 2. Ejemplo de codificación de las respuestas de los estudiantes a la pregunta sobre aprendizajes de capacidades, comportamientos, o cosas asociadas a ser niño/niña

\begin{tabular}{|c|c|}
\hline $\begin{array}{c}\text { ¿Qué te enseñaron sobre capacidades, comportamientos, o cosas que no } \\
\text { podías hacer por ser niño o niña en la FAMILIA? }\end{array}$ & Asociados a \\
\hline $\begin{array}{c}\text { En la casa no nos permitían jugar con las niñas, para no lastimarlas porque los } \\
\text { niños eran más bruscos. (H8) }\end{array}$ & $\begin{array}{c}\text { Capacidad } \\
\text { física }\end{array}$ \\
\hline $\begin{array}{c}\text { La forma de sentarme y siempre me inculcaron que los niños jugaban con } \\
\text { niños y las niñas con las niñas (M39) }\end{array}$ & $\begin{array}{c}\text { Comportamien } \\
\text { to }\end{array}$ \\
\hline $\begin{array}{c}\text { Jugar futbol no me era permitido, aunque me gustaba y me sigue } \\
\text { apasionando. (M13) }\end{array}$ & $\begin{array}{c}\text { Capacidad } \\
\text { física }\end{array}$ \\
\hline no usar aretes, pulseras..., ni vestir rosado. (H30) & $\begin{array}{c}\text { Ropa y } \\
\text { accesorios }\end{array}$ \\
\hline Tener zarcillos, usar prendas rosadas. (M33) & $\begin{array}{c}\text { Ropa y } \\
\text { accesorios }\end{array}$ \\
\hline
\end{tabular}

A continuación, se obtuvo el porcentaje de respuesta asociadas a las denominaciones (códigos) para el ejercicio de comprensión, explicación y crítica, a partir del marco de referencia desde el que se interpretan las unidades discursivas de los estudiantes (Ramírez, 2017). Luego, todo ello se sometió a un ejercicio de triangulación para la articulación de las respuestas proporcionadas, con los elementos conceptuales, y el punto de vista de la investigadora (Cisterna, 2005)

\section{Análisis de los Resultados}

El promedio de edad de los 56 estudiantes (34 mujeres y 22 hombres) es de 33 años, siendo la estudiante más joven una mujer de 19, y el estudiante de más edad, un hombre de 54 años. Pese al lugar de residencia sólo 8,9\% de estudiantes (5) indican ser indígenas, y $5,4 \%$ (3) señalan ser afrocolombianos 0

La Revista Estudios es editada por la Universidad de Costa Rica y se distribuye bajo una Licencia Creative Commons Atribución-NoComercial-CompartirIgual 3.0 Costa Rica. Para más información envíe un mensaje a revistaestudios.eeg@ucr.ac.cr. 
Dossier: Mujeres y Educación en la Universidad Nacional Red de Mujeres Investigadoras de la Universidad Nacional (UNA) afrodescendientes. El promedio de experiencia en aula es de 7 años, siendo la práctica pedagógica del proceso formativo la experiencia del 19,6\% de estudiantes (11 de los 56), mientras 51,8\% (29 estudiantes) tienen más de 5 años de práctica. Vale la pena, entonces, resaltar que una de las características del proceso formativo de la licenciatura en ciencias sociales de la Fundación Universitaria del Área Andina es la homologación de normalistas superiores que desean profesionalizarse, por lo que la experiencia en aula es previa al proceso formativo como profesionales.

Frente a la pregunta: ¿por qué eligió ser docente? Tanto hombres como mujeres coinciden en la existencia de una orientación inscrita en su ser, signada por la necesidad de realizarse y prestar un servicio a la comunidad, a lo que discursivamente se le asignó el código de misión, pero para las mujeres la vocación es la segunda razón, mientras la de los hombres es la pasión por el ejercicio docente.

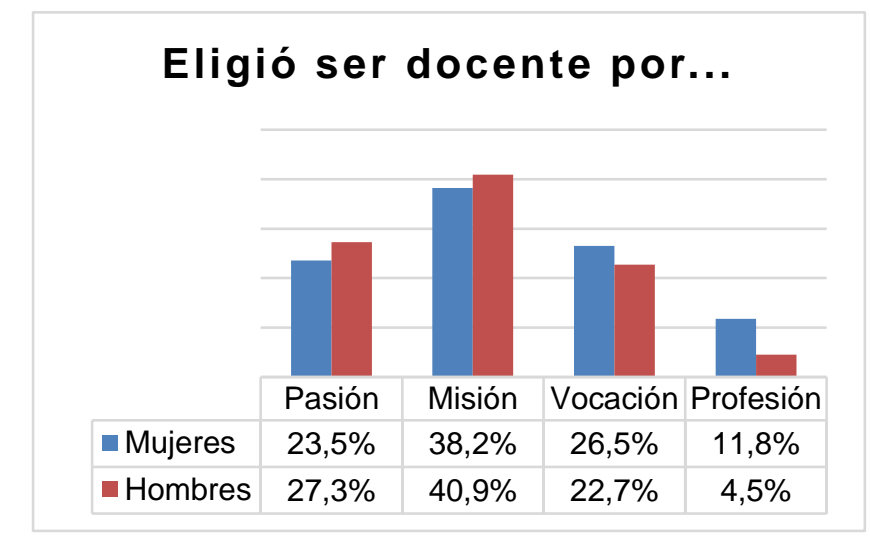

Gráfico 1. Razones para elegir ser docentes
M 40 "porque es una manera de influir positivamente en otros, de hacernos más humanos y de reconocer nuestra humanidad"

H 54 "en la docencia recae la formación de la sociedad del mañana, y quiero aportar en la construcción de un mundo mejor"

\section{(C) $(00$}

La Revista Estudios es editada por la Universidad de Costa Rica y se distribuye bajo una Licencia Creative Commons Atribución-NoComercial-CompartirIgual 3.0 Costa Rica. Para más información envíe un mensaje a 
Dossier: Mujeres y Educación en la Universidad Nacional

Red de Mujeres Investigadoras de la Universidad Nacional (UNA)

Esto guarda relación con lo que consideran vital del rol docente que está referido a guiar/orientar a los estudiantes (fue la respuesta del $35,7 \%$ de los estudiantes), y a las habilidades (sociales y blandas, más que instrumentales) para el ejercicio del rol docente. Al respecto la participante M38 señala que: "El docente debe contar con características de: Escucha activa, respeto, observación, percepción, responsabilidad, compromiso, justicia, apropiación del conocimiento, empatía, amor por su profesión." M38

Llama la atención que con respecto a los miedos de los estudiantes a la hora de desempeñarse como docente exista una diferencia entre hombre y mujeres, primando en los hombres miedos de orden individual-profesionales $(54,5 \%$ de hombres frente a $29,4 \%$ de mujeres) y en las mujeres miedos con respecto a la relación con los demás sujetos de la comunidad educativa (38,2\% de mujeres frente a $22,7 \%$ de hombres).

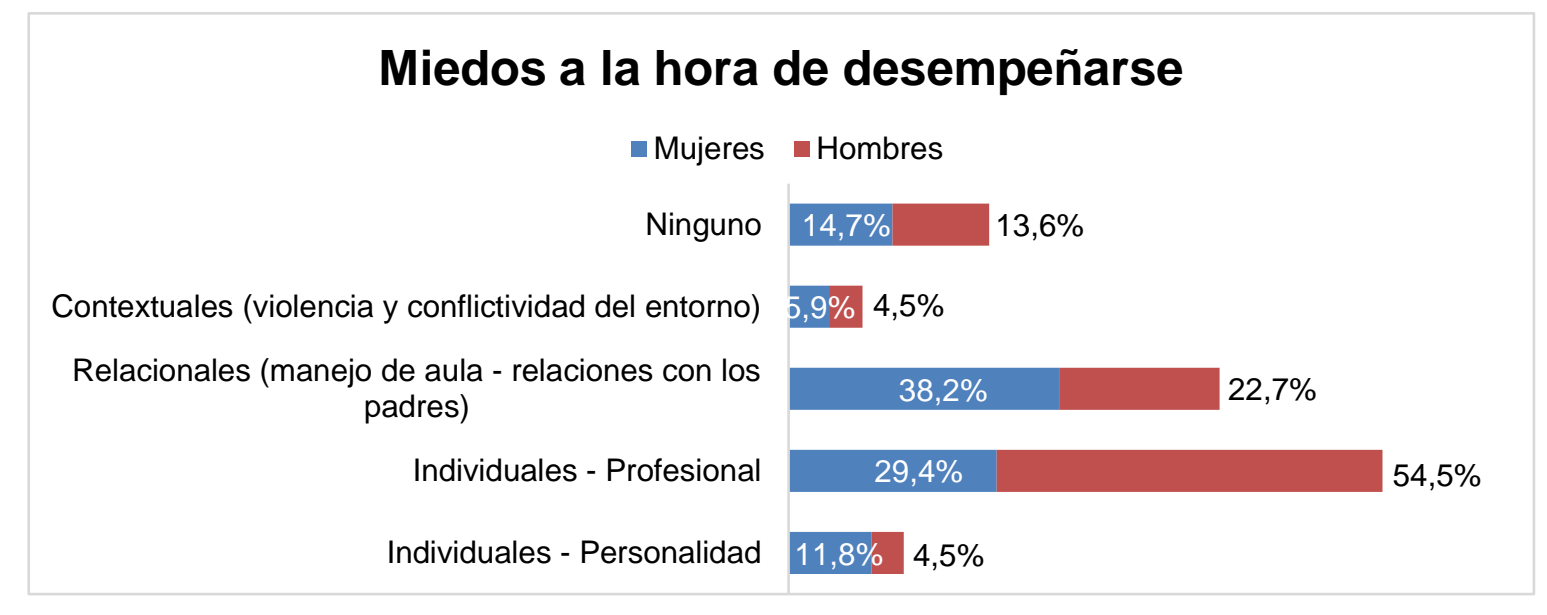

Gráfico 2. Miedos referidos sobre el desempeño como docentes

\section{(ब) $(\Theta \odot$}

La Revista Estudios es editada por la Universidad de Costa Rica y se distribuye bajo una Licencia Creative Commons Atribución-NoComercial-CompartirIgual 3.0 Costa Rica. Para más información envíe un mensaje a 
Dossier: Mujeres y Educación en la Universidad Nacional

Red de Mujeres Investigadoras de la Universidad Nacional (UNA)

Lo que me da miedo a la hora de llevar a cabo el rol docente es "No generar un vínculo y aprendizaje significativo" M31, o "Que los estudiantes no me comprendan la idea" H6. Lo que pareciera reforzar esa mirada dicotómica de las dimensiones de relacionamiento y capacidades intelectuales, en las que la biologización del género señala elementos racionales -asociados a la capacidad profesional- a lo masculino, y elementos de lo emocional a lo femenino.

Los estudiantes mayoritariamente manifiestan entender que el sexo es un atributo biológico, genético, y el género es una construcción cultural, refiriendo que este último puede ser aprendido: "el sexo viene desde que nace, y el género se aprende, por ejemplo en la educación" M11 y "Bueno, la diferencia entre sexo y género, es que el sexo es la forma genética con la que venimos a este mundo, y el género es la manera con la que nos identificamos cada persona" H21. También parten de rasgos de identificación vinculados a las expectativas sociales existentes macho-masculino, hembra-femenina: "El sexo lo dan los órganos genitales y el género la organización de los sustantivos en masculino o femenino" M9 y "el sexo es lo que nos define como hombres o mujeres, género es el grupo al que sientes perteneces" H23.

Más mujeres que hombres confunden sexo y género: "sexo nace con la persona masculino o femenino" M13, y una mujer empleó marcadores lingüísticos de lo místico religioso para responder ¿Cuál es la diferencia entre sexo y género? diciendo: "Hombre y mujer los hizo Dios...que el hombre y la mujer se han desviado dizque en géneros".

Con respecto a los aprendizajes relacionados con capacidades, comportamientos, habilidades, actividades o limitaciones por ser niño o niña, las respuestas de los escenarios de la familia y la escuela se agruparon, identificando

\section{(ब) $(\Theta \odot$}

La Revista Estudios es editada por la Universidad de Costa Rica y se distribuye bajo una Licencia Creative Commons Atribución-NoComercial-CompartirIgual 3.0 Costa Rica. Para más información envíe un mensaje a 
Dossier: Mujeres y Educación en la Universidad Nacional

Red de Mujeres Investigadoras de la Universidad Nacional (UNA)

unidades discursivas que se repetían, y agrupandolas en dimensiones de relacionamiento (manifestaciones socioafectivas, comportamiento, manejo del conflicto), poder-estar (tareas en la vida doméstica, enunciación - uso de la palabra, actividades físicas), saber (áreas académicas y profesionales) y tener (ropa y accesorios, y derechos igualitarios).

Gráfico 3. Aprendizajes sobre el género en la escuela y la familia

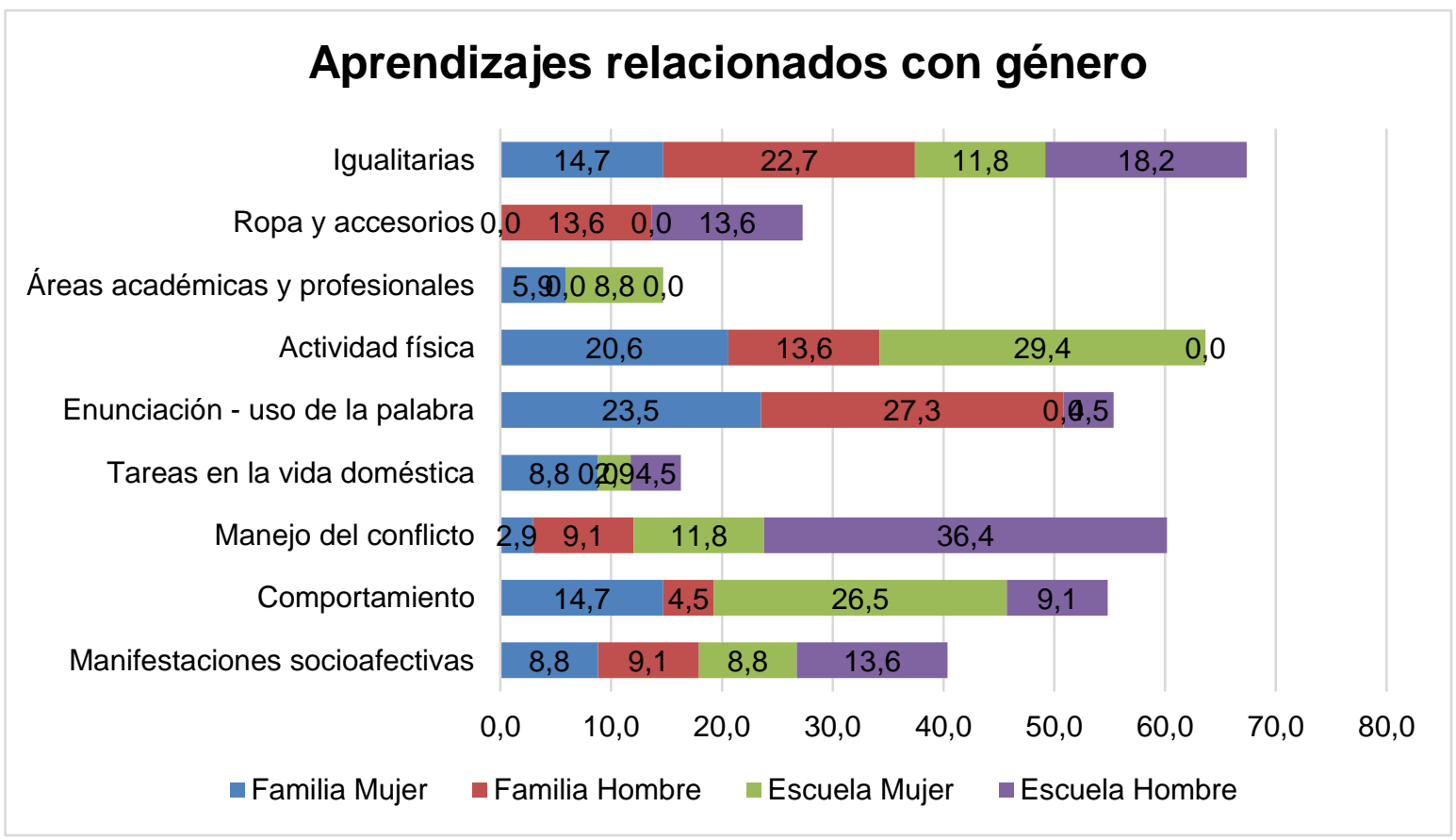

Llama la atención que las mujeres refieran que es en su núcleo familiar donde aprendieron atributos relacionados con el desarrollo de su personalidad (cuándo, dónde y cómo hablar, la mesura o imposibilidad de desarrollar algunas actividades físicas y cómo comportarse) y que reiteren que la escuela refuerza, en lugar de cuestionar y/o resignificar, las capacidades para el desarrollo de actividades físicas

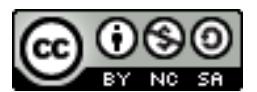

La Revista Estudios es editada por la Universidad de Costa Rica y se distribuye bajo una Licencia Creative Commons Atribución-NoComercial-CompartirIgual 3.0 Costa Rica. Para más información envíe un mensaje a revistaestudios.eeg@ucr.ac.cr. 
Dossier: Mujeres y Educación en la Universidad Nacional

Red de Mujeres Investigadoras de la Universidad Nacional (UNA)

y/o el comportamiento esperado. Por ejemplo, respondieron "las niñas se sientan cruzando las piernas, deben ser de la casa, y no practican deportes de fuerza o rudos" M37, "las mujeres no debemos hablar fuerte o gritar" M48 o "estudié en un colegio femenino y nos dijeron que no podíamos ser bruscas, mal habladas, hacer ejercicios de fuerza para tener la aceptación de todas y todos" M56.

Por su parte, los hombres señalan que ese cuándo, dónde y cómo hablar es aprendido en casa, y que es la escuela la que les permite aprender cómo tramitar los conflictos. Se valora de manera positiva que estén aprendido sobre equidad de género en escuela y casa, y se convierte en un interrogante sobre (el cual volver en otro momento) por qué son más hombres que mujeres los que refieren aprendizajes tendientes al igualitarismo: "la relación entre los dos sexos era por igual, de respeto y aceptación mutua" H55

La naturalización de tareas domésticas como responsabilidad de las mujeres es aprendida por las mujeres en casa ("la mujer es para la casa y el hombre trabaja" M35) y por los hombres en la escuela. El el uso de ropa y accesorios es un aprendizaje que refieren los hombres (y no las mujeres) tanto en la escuela como en la casa: "Muchas veces asociaban los colores a cierto sexo por lo que uno debía decidir acerca de que usar para no hacer parte del sexo contrario" M25 o "no usar aretes, pulseras, jugar con cosas de niñas como muñecas, ni vestir rosado" M26.

Para efectos de identificar la ruptura o continuidad respecto a esta mirada esencialista de atributos en función de la diada sexo-género se tomó como base las dimensiones de la dicotomía asociada a la biologización del género (Ver Tabla 1) y se agruparon en dimensiones de emocionalidad, relacionamiento, capacidades intelectuales y niveles de actividad.

\section{(C) $(0 \odot$}

La Revista Estudios es editada por la Universidad de Costa Rica y se distribuye bajo una Licencia Creative Commons Atribución-NoComercial-CompartirIgual 3.0 Costa Rica. Para más información envíe un mensaje a 
Dossier: Mujeres y Educación en la Universidad Nacional

Red de Mujeres Investigadoras de la Universidad Nacional (UNA)

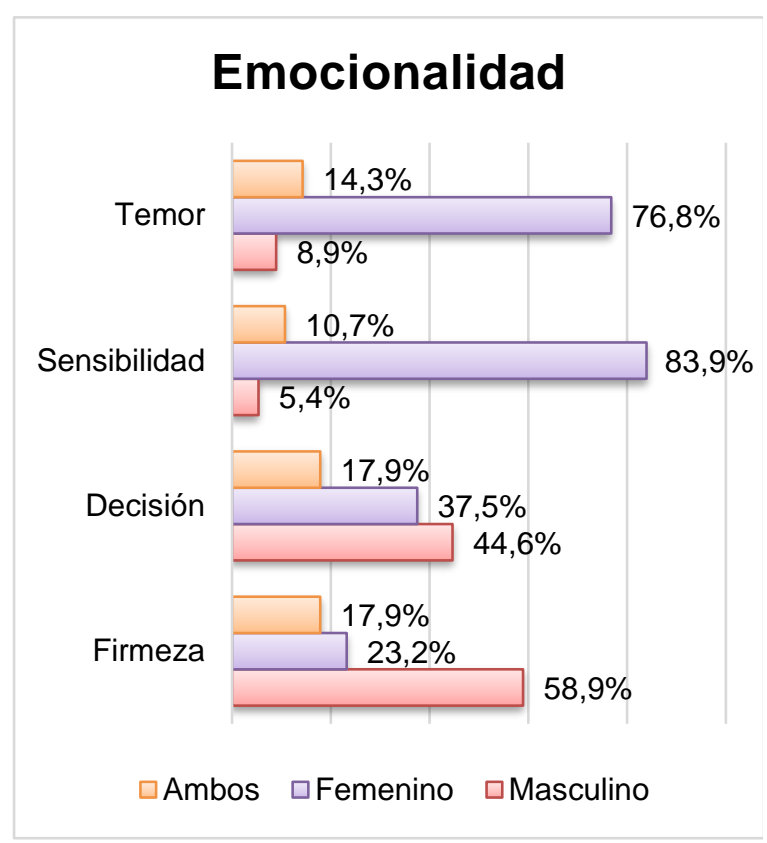

Gráfico 4. Atributos de géneros sobre la emocionalidad

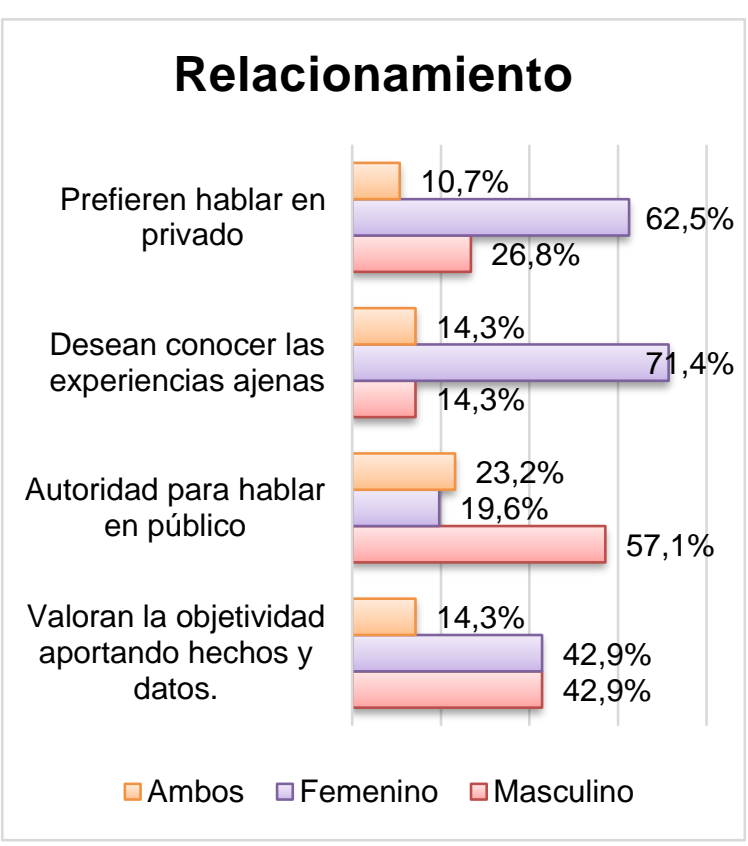

Gráfico 5. Atributos de géneros sobre el relacionamiento

\section{(ब) $(\Theta \odot$}

La Revista Estudios es editada por la Universidad de Costa Rica y se distribuye bajo una Licencia Creative Commons Atribución-NoComercial-CompartirIgual 3.0 Costa Rica. Para más información envíe un mensaje a revistaestudios.eeg@ucr.ac.cr. 
Dossier: Mujeres y Educación en la Universidad Nacional

Red de Mujeres Investigadoras de la Universidad Nacional (UNA)

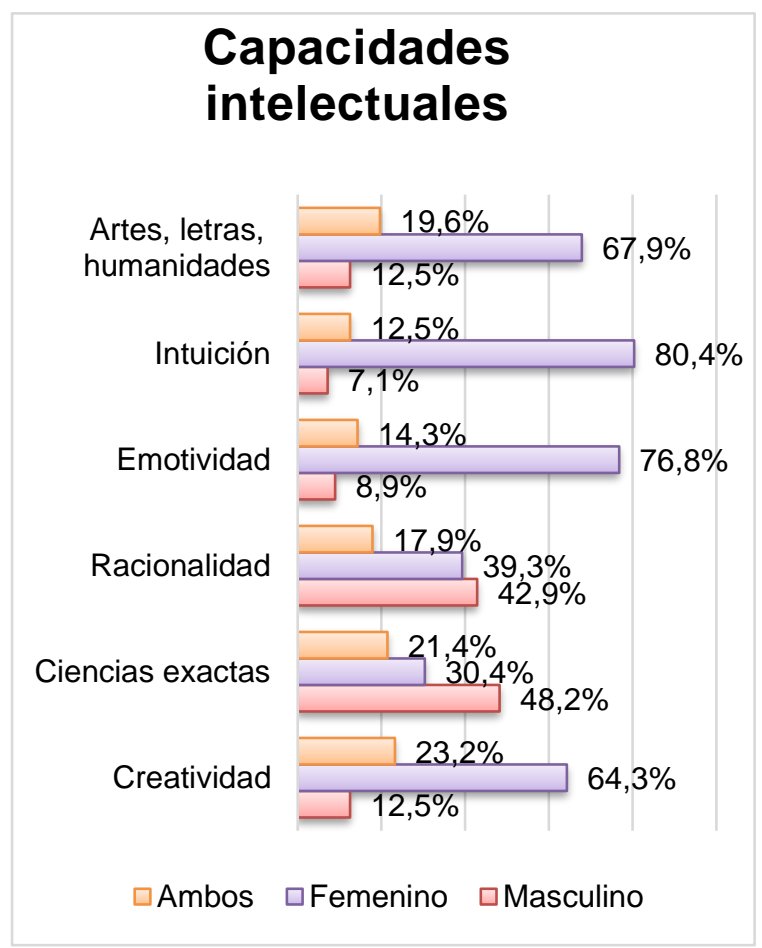

Gráfico 6. Atributos de géneros sobre las capacidades intelectuales

\section{Niveles de actividad}

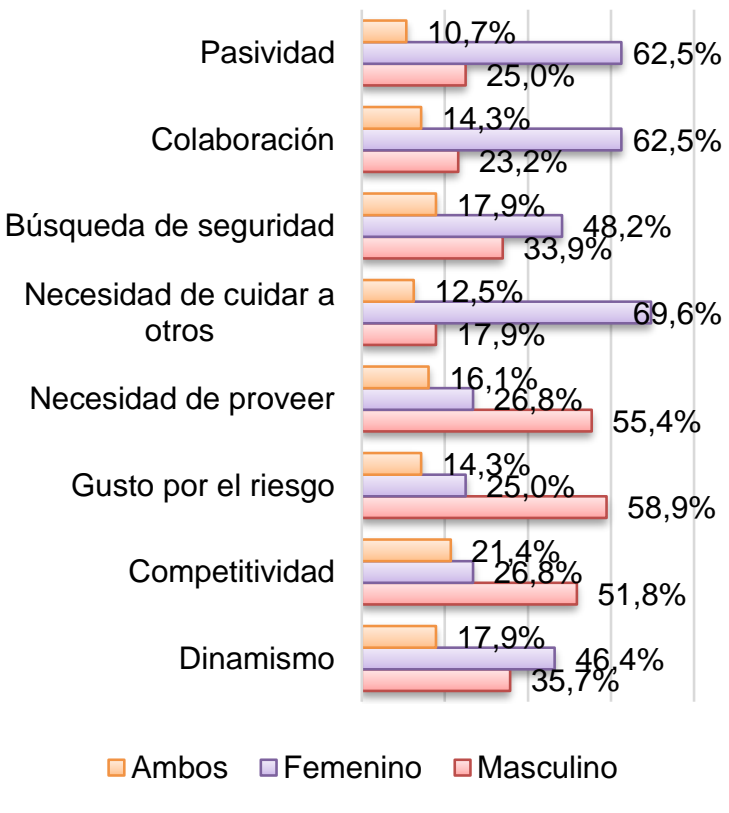

Gráfico 7. Atributos de géneros sobre los niveles de actividad

Como se observa de los gráficos 4 al 7, los estudiantes siguen dando respuestas esencialistas vinculadas a la diada sexo-género, relacionando sensibilidad (83,9\%) deseo de conocer experiencias ajenas 71,4\%), intuición $(80,4 \%)$, y necesidad de cuidar a otros $(69,6 \%)$ características atribuidas a lo femenino, mientras las características atribuidas a lo masculino no obtuvieron porcentajes tan elevados, siendo los atributos más relevante el gusto por el riesgo $(58,9 \%)$ y la firmeza $(58,9 \%)$

\section{(c) (7) (2)}

La Revista Estudios es editada por la Universidad de Costa Rica y se distribuye bajo una Licencia Creative Commons Atribución-NoComercial-CompartirIgual 3.0 Costa Rica. Para más información envíe un mensaje a revistaestudios.eeg@ucr.ac.cr. 
Dossier: Mujeres y Educación en la Universidad Nacional

Red de Mujeres Investigadoras de la Universidad Nacional (UNA)

Del rol docente, el sentir el llamado a guiar/orientar, es coherente con las respuestas sobre sentir que la docencia es una misión (ver gráfico 1). Quienes dieron respuestas sobre disciplinar, son los normalistas, y esto se explica porque han interiorizado una concepción de la formación orientada hacia la necesidad de inculcar valores y conservar el orden.

Gráfico 8. Respuestas sobre el rol del docente

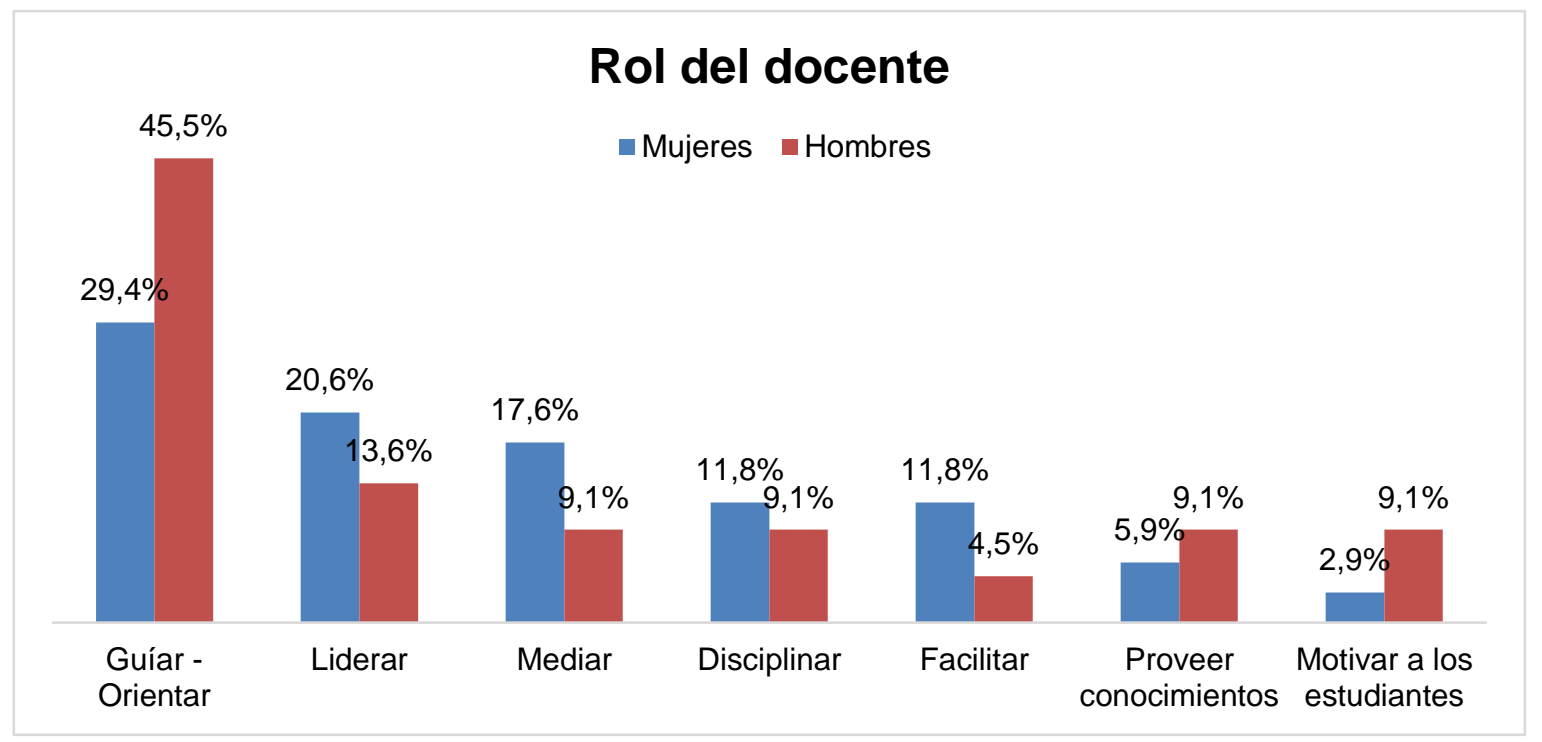

Finalmente, frente a las habilidades, actitudes y saberes necesarios para desempeñarse como licenciados en Ciencias Sociales, las respuestas de los estudiantes se agruparon de acuerdo a la clasificación de Lozano y Herrera (2013).

\section{(ब) $\odot \odot$}

La Revista Estudios es editada por la Universidad de Costa Rica y se distribuye bajo una Licencia Creative Commons Atribución-NoComercial-CompartirIgual 3.0 Costa Rica. Para más información envíe un mensaje a revistaestudios.eeg@ucr.ac.cr. 
Dossier: Mujeres y Educación en la Universidad Nacional

Red de Mujeres Investigadoras de la Universidad Nacional (UNA)

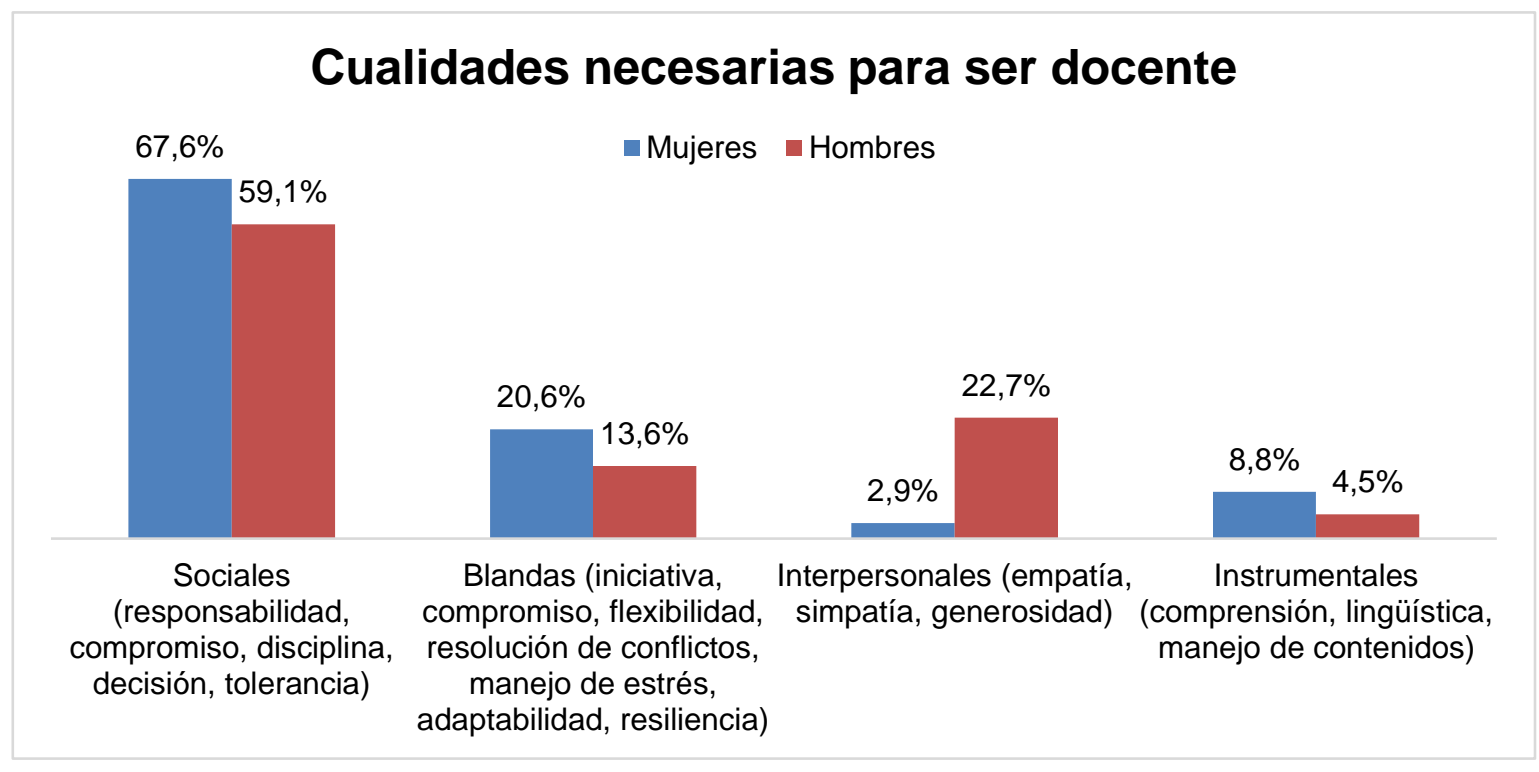

Gráfico 9. Agrupación de respuestas sobre cualidades necesarias para ser docente

Pese a que en el resto de las respuestas se vinculó la emocionalidad a mujeres, y a lo femenino, los hombres refieren, más que las mujeres, cualidades interpersonales (como empatía, simpatía, generosidad), mencionando que se requiere "empatía, solidaridad" M14 y ser "asertivo, presto a escuchar, ser un buen orientador" H49. Las mujeres hablan de habilidades sociales como "compromiso, dedicación, pasión, entereza y responsabilidad" H40.

\section{(c) (†) (-)}

La Revista Estudios es editada por la Universidad de Costa Rica y se distribuye bajo una Licencia Creative Commons Atribución-NoComercial-CompartirIgual 3.0 Costa Rica. Para más información envíe un mensaje a revistaestudios.eeg@ucr.ac.cr. 
Dossier: Mujeres y Educación en la Universidad Nacional

Red de Mujeres Investigadoras de la Universidad Nacional (UNA)

\section{Conclusión}

La práctica pedagógica en la Licenciatura en Ciencias sociales de la Fundación Universitaria del Área Andina se constituye en un espacio de fortalecimiento de la formación docente en el que convergen los saberes disciplinares y pedagógicos mediante el ejercicio en contextos educativos propios, pero que también posibilita conversar acerca de la subjetividad docente.

Aunque las instituciones familia y escuela se han transformado, persisten algunos estereotipos de género alrededor de las características y comportamientos asociados con lo que una mujer docente puede hacer, a partir de la diferenciación entre lo masculino y lo femenino (género). Allí, y de acuerdo a la lógica de los contrarios que hace parte de la construcción del pensamiento dicotómico-dualista de la cultura occidental algunos estudiantes siguen asumiendo que características de emocionalidad, orientación a lo "artístico", cooperación y transmisión de la voz masculina son propias de las docentes mujeres o feminizada, mientras que la racionalidad, la competencia y la creación de conocimiento son menos frecuentes en mujeres.

Los estudiantes han dejado de ver la docencia como una profesión "femenina", pero siguen resaltando el rol de cuidado de las mujeres docentes, y -en tanto la escuela es una institución que transmite o transforma valores y creencias-, la persistencia de estereotipos de género en las y los docentes resulta preocupante si se tiene en mente superar la desigual valoración de hombres y mujeres (en detrimento de estas últimas).

El rol de la educación en el empoderamiento de la mujer es fundamental. Las enseñanzas encaminadas al desarrollo de la personalidad se transmiten en la familia y se refuerzan o cuestionan en la escuela. En tanto docentes, este segundo 
Dossier: Mujeres y Educación en la Universidad Nacional

Red de Mujeres Investigadoras de la Universidad Nacional (UNA)

ámbito de actuación o escenario de socialización va a posibilitar romper la mirada de subordinación de lo femenino, contribuyendo a una equidad de géneros y/o a superar la mirada esencialista que parte de la biologización del género.

Como coexisten varias perspectivas y énfasis sobre la relación docenciagénero, superar la mirada de que en el universo de las mujeres docentes existe (por su propia naturaleza femenina) una misión y/o llamado por el cuidado de los otros. Esto hace imprescindible que se siga trabajando para que los futuros licenciados cuestionen la biologización del género y reconozcan que la posibilidad de construir conocimiento, desarrollar tareas con criterios de "racionalidad" y "objetividad" no son exclusivas de los hombres y/o de los sujetos masculinizados.

Prácticas cotidianas con los estudiantes, como el desarrollo de actividades físicas, la organización de tareas cuando se proponen trabajos en equipo, la elección de quienes asumen la vocería en los trabajos, la valoración de las emociones y "la voz propia" al escribir, la no condena o subvaloración de "lo subjetivo" y superar la mirada del cuidado del otro como algo feminizado pueden contribuir a cuestionar la naturalización de la división sexo genérica del mundo.

En las prácticas de formación reconocer las creencias frente a la relación mujer-docente se constituye en una posibilidad para desnaturalizar el cuidado como algo exclusivamente femenino, la relación dicotómica objetivo/subjetivo como propio de lo masculino/femenino, y podrían ser una vía para que los estudiantes que van a ser formados por estos maestros vayan configurando subjetividades génerosensibles en las que hombres y mujeres sean vistos en igualdad de capacidades, habilidades y destrezas.

\section{(C) $(\Theta \odot$}

La Revista Estudios es editada por la Universidad de Costa Rica y se distribuye bajo una Licencia Creative Commons Atribución-NoComercial-CompartirIgual 3.0 Costa Rica. Para más información envíe un mensaje a 
Dossier: Mujeres y Educación en la Universidad Nacional Red de Mujeres Investigadoras de la Universidad Nacional (UNA)

\section{Referencias}

Achilli, E. L. (2000). Investigación y formación docente, Colección Universitas, Serie Formación Docente, Laborde Editor.

Altamirano, G. (1993). Estereotipos de género en la terapia psiquiátrica en Educación y Género: una propuesta pedagógica. Santiago de Chile. Ediciones La Morada - Ministerio de Educación

Beauvoir, S. (1949). El segundo sexo. Ediciones cátedra, Madrid.

Boff, L. y Muraro, R. M. (2004) Femenino y Masculino: Una nueva conciencia para el encuentro de las diferencias. Editorial Trotta

Bolaños, L. y Jiménez, R. (2007). La formación del profesorado en género. Revista de Investigación Educativa, 25 (1), 77-95.

Bronfenbrenner, U. (2002). La ecología del desarrollo humano: experimentos en entornos naturales y diseñados. Barcelona: Paidós

Cisterna F, (2005). Categorización y triangulación como procesos de validación del conocimiento en investigación cualitativa. theoria, 14(1), 61-71. Recuperado de: http://www.redalyc.org/pdf/299/29900107.pdf

Cristancho, J. G. (2012). Los conceptos sujetos y subjetivación política. Propedéutica para una reflexión. documento presentado en el seminario "Memoria y subjetividad política en el cine colombiano de la última década", Bogotá, UPN.

De Lauretis, T. (1996). La tecnología del género. Revista Mora, Vol. 2 , 6-34.

\section{(c) (i)(2)}

La Revista Estudios es editada por la Universidad de Costa Rica y se distribuye bajo una Licencia Creative Commons Atribución-NoComercial-CompartirIgual 3.0 Costa Rica. Para más información envíe un mensaje a revistaestudios.eeg@ucr.ac.cr. 
Dossier: Mujeres y Educación en la Universidad Nacional

Red de Mujeres Investigadoras de la Universidad Nacional (UNA)

Izquierdo, M. ${ }^{a}$ Jesús (1994): "Uso y abuso del concepto de género". En Vilanova, Mercedes (comp.): Pensar las diferencias, Barcelona, Universidad de Barcelona (SIM), Institut Catalá de la Dona. 31-53.

Lamas, M. (2006). Género: algunas precisiones conceptuales y teóricas. Feminismo. Transmisiones y retransmisiones. Recuperado de: https://redmujeresjusticia.org.ar/wp-content/uploads/2019/03/Ge\%CC\%81neroalgunas-precisiones-conceptuales-y-teo\%CC\%81ricas-Lamas.pdf

Lamas, M. (2007). Género: claridad y complejidad. Recuperado de: http://www.yorku.ca/hdrnet/images/uploaded/un genero\%20lamas.pdf.

Lozano, A., \& Herrera, J. (2013). Diseño de programas educativos basados en competencias. Editorial Digital del Tecnológico de Monterrey.

Perrenoud, P. (2007). Desarrollar la practica reflexiva en el oficio de enseñar: profesionalización y razón pedagógica. Colección critica y fundamentos (España).

Ramírez, F. (2017). Inclusión educativa de estudiantes sexualmente diversos en Colombia, periodo 2000 - 2015. Tesis de doctorado en educación. Universidad Santo Tomás, Colombia. Recuperado de: https://repository.usta.edu.co/handle/11634/4074

Schön, D. (2002). La formación de profesionales reflexivos. Hacia un nuevo diseño de la enseñanza y el aprendizaje en las profesiones. Barcelona: Paidós.

Shulman, L. S. (2005). Signature pedagogies in the professions. Daedalus, 134(3): 52-59. doi: 10.1162/0011526054622015

\section{(c) (i) (2)}

La Revista Estudios es editada por la Universidad de Costa Rica y se distribuye bajo una Licencia Creative Commons Atribución-NoComercial-CompartirIgual 3.0 Costa Rica. Para más información envíe un mensaje a 
Dossier: Mujeres y Educación en la Universidad Nacional

Red de Mujeres Investigadoras de la Universidad Nacional (UNA)

Sultana, R. G. (2009). Competence and competence frameworks in career guidance: complex and contested concepts. International Journal for Educational and Vocational Guidance, 9(1), 15-30.

Vasilachis, I. (2019) Estrategias de investigación cualitativa: Volumen II (Vol. 240022). Editorial Gedisa.

Villa, A., y Poblete, M. (2007). Aprendizaje basado en competencias. Una propuesta para la evaluación de las competencias genéricas. Bilbao: Universidad de Deusto

Yuan, R., \& Burns, A. (2017). Teacher identity development through action research: A Chinese experience. Teachers and Teaching, 23(6), 729-749.

\section{Notas Finales}

\footnotetext{
' Beauvoir, S. (1949). El segundo sexo. Ediciones cátedra, Madrid. P. 371.

ii La universidad cuenta actualmente con 53 CSU en todo el país, y 3 sedes (Bogotá, Pereira y Valledupar)
}

\section{(c) (i) (9)}

La Revista Estudios es editada por la Universidad de Costa Rica y se distribuye bajo una Licencia Creative Commons Atribución-NoComercial-CompartirIgual 3.0 Costa Rica. Para más información envíe un mensaje a revistaestudios.eeg@ucr.ac.cr. 